\title{
An analysis of university students who are smokers according to their levels of addiction
}

\author{
Cem Gercek $^{1 \mathrm{a}}$ \\ ${ }^{1}$ Faculty of Education, Department of Mathematics and Science Education, Hacettepe University, \\ Ankara, Turkey
}

\begin{abstract}
Young people constitute one fifth of world population. Youth's reasons for smoking include looking for excitement, getting away from problems and meeting emotional and social needs. Smoking addiction is the most common addiction among young people especially due to the fact that cigarettes are sold legally, and it is known that one out of two young people who try smoking become addicted. Being knowledgeable about youth's smoking addiction will also raise the effects of health education activities. This study aims to evaluate the smoking addiction levels of university students who smoke. Thus, it uses survey model- which is one of quantitative research methods. The study group was composed of 93 volunteering university students chosen randomly. The research data were collected with Fagerström Nicotine Addiction Test. The data collected were put to descriptive analysis (percentages, frequencies, etc.). Accordingly, it was found that the majority of the participants had low or very low levels of smoking addiction, and that male students were more addicted than female students. The reason most commonly mentioned by the participants for taking up smoking was the circle of friends, while the reason for why they were smoking was their feeling of relaxation.
\end{abstract}

Keywords: Students, smoking, addiction, health education

\section{Introduction}

Smoking is an important problem of public health. According to the data coming from World Health Organisation, smoking has been increasingly continuing even though its negative effects are known to all [1]. It is predicted that the rate of smokers will increase at least by $50 \%$ until the year 2025 . Smoking has risks not only for smokers but also for nonsmokers. If smoking continues at this pace, it is certain that smoking-related deaths will increase.

Young people constitute one fifth of world population. Young population in the 10-19 age range is above one billion. $80 \%$ of them are in developing countries. Youth's reasons for smoking include looking for excitement, getting away from their problems and meeting their emotional and social needs. Especially because it is legal to sell cigarettes, smoking

\footnotetext{
${ }^{\mathrm{a}}$ Corresponding author: cgercek@hacettepe.edu.tr
} 
addiction is the most common addiction type among young people; and it is known that on out of two young people who try smoking become addicted [2].

The ratio of smokers in men aged 15 or above is $63 \%$ in Turkey whereas the rate is $24 \%$ for women. $20 \%$ of smokers start smoking at ages $11-14,39 \%$ at ages $15-18$ and $49 \%$ start smoking after age 18. Research conducted by Turkish Statistical Institute (TUIK) found that $31 \%$ of individuals aged 15 and above smoke tobacco every day or occasionally [3]. Despite efforts to make them quit smoking or hindering their smoking, individuals could not be prevented from starting smoking or they could not be made to quit smoking. Therefore, investigating the reasons especially for youth to start smoking is important in that it sheds light on precautions that can be taken in this respect.

Smoking is an important health problem among university students [4, 5]. Individuals' social life and life in their circle in earlier ages shape their perspectives and beliefs in relation to smoking (see Figure 1). Individuals with positive attitudes towards smoking have more tendency than non-smokers to smoke [4]. Besides, positive attitudes also cause supporting and arguing for smoking. Research conducted with 3101 first year university students demonstrated that the rate of students who had tried smoking only once was $58 \%$ while the rate of those who were still smoking was $22 \%$ [2]. To illustrate the case with examples from the world, the rate of smokers among university students in Syria is $23 \%$ [6], it is 29\% in Jordan [7], 14\% in Saudi Arabia [8], 17-32\% in African countries [9] and $22 \%$ in European countries [10]. Another study found that smoking young people were less knowledgeable about the harmful effects of smoking than those who had never smoked or who had given up smoking [11]. In parallel to this, another study conducted with university students found that individuals who had been smoking for longer had reduction in selfefficacy beliefs [12]. Türkoğlu (2007) demonstrated that there were positive correlations between addicted people and nicotine addiction [13].

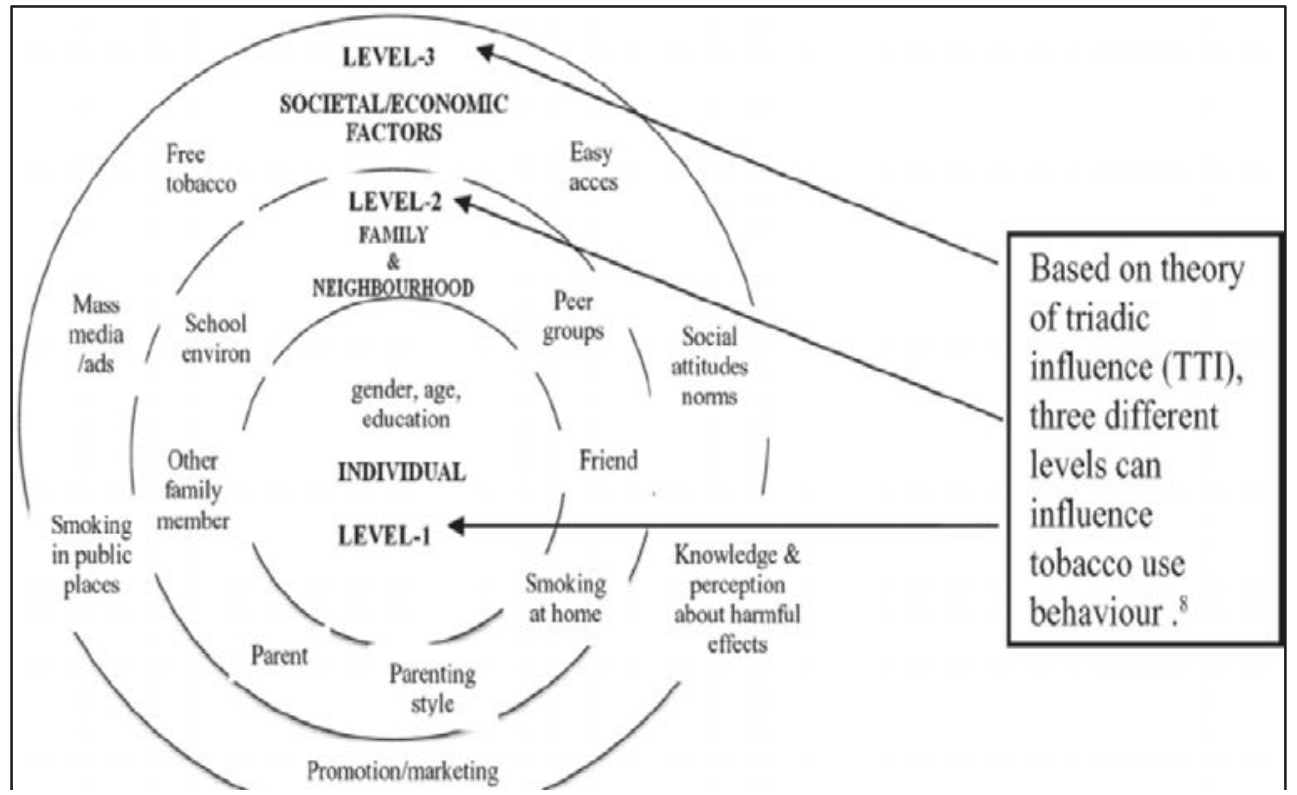

Fig. 1. The Conceptual Framework of Adolescent Tobacco Use Behaviour by Flay and Petraitis (1994).

One of the reasons why young people are inclined to smoking is that they ignore health problems that can emerge. The fact that smoking-related health problems do not arise 
immediately or that they are not noticed very soon is also an important factor in addiction. However, starting smoking or becoming addicted to smoking will cause negative effects on those individuals' life in the following years. More than 150 million young people smoke all over the world, and it is estimated that they will die of a smoking-related disease [2].

The number of cigarettes smoked a day was found to be directly proportional to age. Accordingly, the number of cigarettes smoked a day increases in parallel to the increase in age. This is important in quitting smoking and in the emergence of serious health problems. The findings obtained demonstrate that there should be struggle against starting smoking at earlier ages [15]. In this context, becoming knowledgeable about young people's smoking addiction will increase the effects of health education activities.

\subsection{Aim of the Study}

This study aims to analyse the smoking addiction levels of university students who smoke. In accordance with this purpose, the study seeks answers to the following questions:

1. 1. What are the smoking addiction levels of students who smoke, and what is the distribution of the levels according to gender?

2. 2. What are the students' reasons for starting smoking?

3. 3. What do students feel while smoking?

\section{Method}

This is a study conducted in survey model- which is one of quantitative research methods.

\subsection{Study Group}

The study group was composed of 93 students 44 of whom were female and 49 of whom were male students attending various faculties of the universities chosen randomly in 20172018 academic year. Having informed the students of the study, they were asked to participate on the basis of volunteering. The average age of the students attending Science, Architecture, Engineering, Medical, Law, Educational and Economic and Administrative Sciences faculties was 23 . The age of starting smoking was 17 on average; and the length of time they had been smoking was approximately 6 years.

\subsection{Data Collection Tools}

Fagerström Nicotine Addiction Test was used as the tool of data collection [16]. The test was translated into Turkish by Uysal et al in 2004 [17], and validity and reliability analyses were done. Fagerström Nicotine Addiction Test (FNAT) contained 6 questions in total. The test evaluates smokers' levels of addiction in 5 categories. Accordingly, scores of 0-2 points are labelled as low level addiction, 5 points as medium level addiction and 6-7 points as high level addiction. After the study group was given this test, they were asked two more questions about their reasons for starting smoking and what they felt while smoking.

\subsection{Data Analysis}

The data collected with FNAT were put to descriptive statistical analyses (frequencies, frequencies, etc.) and thus evaluated. 


\section{Findings}

The findings are evaluated in this section in line with the purpose of this study. Accordingly, addiction levels and the distribution of the levels according to gender were analysed in the context of the first research question. In consequence, it was found that $34 \%$ of the students had very low level of smoking addiction whereas $30 \%$ had low level and $8 \%$ had medium or high level of addiction. The distribution of the levels according to gender is shown in Table 1 . Of female students, $34 \%$ had very low level of addiction, $41 \%$ had low level of addiction, $11 \%$ had medium level of addiction, $10 \%$ had high level of addiction and $4 \%$ had very high level of addiction to smoking. Of male students, on the other hand, $35 \%$ had very low level, $21 \%$ had low level, $16 \%$ had medium level, $18 \%$ had high level and $10 \%$ had very high level of cigarette addiction.

Table 1. The distribution of addiction levels according to gender

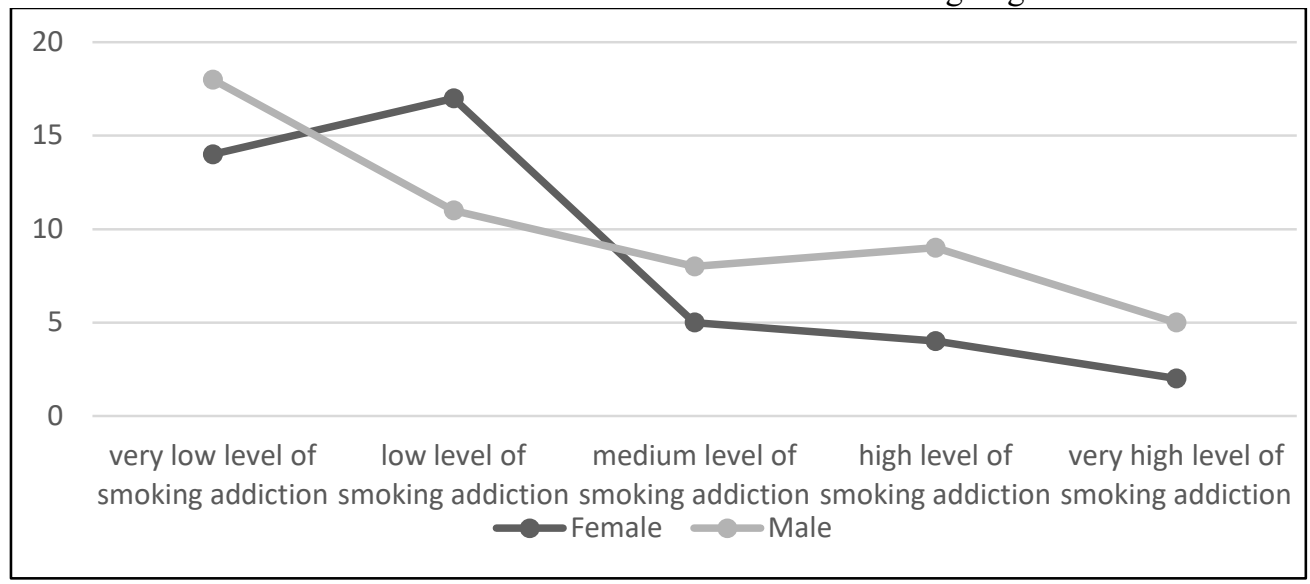

The reasons for starting smoking were determined based on the second research question. Accordingly, the reasons found included such elements as circle of friends (46\%), stress $(17 \%)$, curiosity $(16 \%)$, pleasure $(9 \%)$, emulation $(8 \%)$ and proving oneself to others (3\%). The participants mentioned separating from a friend, school, sorrow and boredom as stress; they talked of entertainment, attracting attention as pleasure; and they talked about being influenced by their father, friends, elder brothers and other elderly people as emulation. A student said "I don't know" (1\%).

In accordance with the third research question, the feelings they had while smoking were determined. They listed such feelings as relaxation (36), happiness (10), pleasure (9) enjoyment (4), different (3), good (3), confidence (2), bad (2), obligation (3), clearance in lungs (1), pride (1), need to quit (1) and liking. 11 of the smokers said they felt nothing while smoking whereas 3 did not want to answer the question.

\section{Conclusion and Discussion}

This study determined the addiction levels of university students attending different faculties. Accordingly, the addiction levels were found to be low and very low. On analysing smoking addiction according to gender, it was found that most of the female students had low levels of addiction and that male students had very low levels of addiction. Yet, it was observed that male students had higher levels of smoking addiction 
than female students. Research conducted in Turkey in relation to smoking has shown that male students had higher levels of smoking addiction than female students [1, 2, 3].

The reason for starting smoking participants mentioned most frequently was the circle of friends. According to Özcebe (2008), having a friend who is a smoker increases the risk for the young to start smoking 3-4 times. Apart from that, the participants also mentioned such reasons as stress, curiosity, pleasure, emulation and proving oneself to others, respectively. The students talked about separating from their boyfriend/girlfriend, school environment, sorrow, examinations and boredom as the sources of stress as the cause for starting smoking. They talked about entertainment, attracting interest and enjoyment as the source of pleasure; and they talked about their father, friends and elder brothers as the source of emulation. Having a smoker father and mother increases the probability of the young to smoke twice [2]. In addition to that, such factors as insufficient relations with their family and copying others also facilitate young people to start smoking. Several studies conducted emphasise that taking others as a model, immediate surrounding and friends are influential in starting to smoke.

Students who smoke said that they mostly felt positive things such as relaxation, happiness, pleasure, good, pride, good and liking while smoking. Those who felt relaxation made such descriptions as having a rest, calming down, fulfilling their responsibility and like tea. Yet, some of the students also mentioned negative feelings such as something lacking, different, bad, obligation and need to quit. In addition to that the students who said that they felt enjoyment while they were smoking made statements such as "although I know it is harmful", "as a feeling of obligation" and "fulfilling the responsibility"; on the other hand, the students who felt bad made statements such as hopelessness, regret, and feeling good even though knowing that it is bad. Smokers stated that they felt relaxed, they solved their problems, they organised their thoughts and that they had better social communication [12]. Some research report that cigarettes smoked so as to reduce stress increase the levels of concern and stress as the number of cigarettes increases and that it diminishes self-efficacy beliefs. Addiction develops in this context. More physiological and psychological problems will emerge in addicted people.

The findings obtained in this study are considered important in organising activities about education on smoking. However, this study is restricted to university students and to FNAT. Therefore, conducting further studies is important for primary prevention for young people's starting to smoke.

\section{References}

1. WHO MPOWER package. WHO report on the global tobacco epidemic. Denmark: Publications WHO regional office for Europ. (2008).

2. H. Özcebe, Gençler ve Sigara [Adolecents and Smoke]: Ministry of Health (Report No: 731) Retrieved October $3, \quad 2017$ from https://sbu.saglik.gov.tr/Ekutuphane/kitaplar/t18.pdf (2008, February).

3. TUIK, Global adult tobacco survey, publication number: 3324, Turkey: Turkish Statistical Institute, Printing Division, Ankara (2008).

4. M. R. Gillmore, E. A. Wells, E. E. Simpson, D. M. Morrison, M. J. Hoppe, A. A. Wilsdon, E. Murowchick, Children's beliefs about smoking, Nicotine \& Tabocco Research, 4(2), 177-183 (2002).

5. W. G. Shadel, R. Niaura, D. B. Abrams, How do adolescents process smoking and antismoking advertisements? a social cognitive analysis with implications for understanding smoking 1nitiation, Rev. of General Psychol., 5, 429-444 (2001). 
6. W. Maziak, S. Rastam, T. Eissenberg, T. Asfar, F. Hammal, M. Bachir, Gender and smoking status based analysis of views regarding waterpipe and cigarette smoking in Aleppo, Syria. Preventive Medicine, 38(4), 479-484 (2004).

7. L. G. Haddad, M. Z. Malak, Smoking habits and attitudes towards smoking among university student in Jordan. Int. J. of Nursing Studies, 39(8), 793-802 (2002).

8. A. Mandil, M. A. BinSaeed, R. Dabbagh, S. A. Shaikh, M. AlSaadi, M. Khan, Smoking among Saudi university students: consumption patterns and risk factors. Eastern Mediterranean Health J., 17(4), 309-316 (2011).

9. L. Mpabulungi, A. S. Muula, Tobacco use among high school student in Kampala, Uganda. Croatian Medical J., 45(1), 80-83. (2004).

10. T. Baska, W. C. Warren, M. Baskova, N. R. Jones, Prevalence of youth cigarette smoking and selected social factors in 25 European countries. Int. J. of Public Health, 54(6), 439-445 (2009).

11. M. A. Freeman, E. V. Hannessy, D. M. Marzullo, Defensive evaluation of smoking messages among college-age smokers: The role of possible selves. Health Psychology, 20, 424-433 (2001).

12. H. Yazıc1, Y. Özbay, Examining the relationship between smoking behavior and selfefficacy beliefs of university students, Sakarya Üniversity Journal of Education Faculty, 7, 91-107 (2004).

13. M. Türkoğlu, Adnan Menderes Üniversitesi öğrencilerinin sigara içme ve birakma davranışlarının değerlendirilmesi. Basılmamış uzmanlık tezi. Adnan Menderes Üniversitesi Tıp Fakültesi Aile Hekimliği Anabilim Dalı, Aydın (2007).

14. B. R. Flay, J. Petraitis, The theory of triadic influence: A new theory of health behaviour with implications for preventive interventions. Advences in Medical Sociology, 4, 19-44 (1994).

15. A. Yıldırım Kaptanoğlu, G. Polat, M. Soyer, The relation between smoking habit among the students and faculty members in Marmara university and steady cost of smoking. Journal of Higher Education and Science, 2(2), 119-125 (2012).

16. T. F. Heatherton, L. T. Kozlowski, R. C. Frecker, K. O. Fagerström, The Fagerström Test for nicotine dependence: a revision of the fagerström tolerance questionnaire. British J. of Addiction, 86, 1119-1127 (1991).

17. M. A. Uysal, F., Kadakal, C., Karşıdăg, G., Bayram, O., Uysal, V. Yılmaz, Fagerström test for nicotine dependence: Reliability in a Turkish sample and factor analysis. Tuberculosis and Thorax, 52(2), 115-121 (2004). 